\title{
Structure of the Human Cytochrome c Oxidase Subunit Vb Gene and Chromosomal Mapping of the Coding Gene and of Seven Pseudogenes
}

\author{
Margaret I. Lomax, ${ }^{\star}$ Chin-Lin Hsieh, † Basil T. Darras, $†$ and Uta Francke \\ *Department of Anatomy and Cell Biology, University of Michigan, Ann Arbor, Michigan 48109; †Department of Genetics \\ and Howard Hughes Medical Institute, Stanford University Medical Center, Stanford, California 94305; \\ and $\ddagger$ Department of Pediatrics, New England Medical Center, Boston, Massachusetts 02111 \\ Received September 14, 1990; revised December 14, 1990
}

Subunit Vb of mammalian cytochrome c oxidase (COX; EC 1.9.3.1) is encoded by a nuclear gene and assembled with the other $12 \mathrm{COX}$ subunits encoded in both mitochondrial and nuclear DNA. We have cloned the gene for human COX subunit $\mathrm{Vb}(C O X 5 B)$ and determined the exon-intron structure by both hybridization analysis and DNA sequencing. The gene contains five exons and four introns; the four coding exons span a region of approximately 2.4 kb. The $5^{\prime}$ end of the $C O X 5 B$ gene is GC-rich and contains many HpaII sites. Genomic Southern blot analysis of human DNA probed with the human COX Vb cDNA identified eight restriction fragments containing $\mathrm{COX} \mathrm{Vb}$-related sequences that were mapped to different chromosomes with panels of human $\times$ Chinese hamster somatic cell hybrids. Because only one of these fragments hybridized with a 210-bp probe from intron 4 , we conclude that there is a single expressed gene for $\mathrm{COX}$ subunit $\mathrm{Vb}$ in the human genome. We have mapped this gene to chromosome 2 , region cen-q13. 1991 Academic Preas, Inc.

\section{INTRODUCTION}

Cytochrome $c$ oxidase (COX; EC 1.9.3.1), the terminal enzyme of the electron transport chain, transfers electrons from reduced cytochrome $c$ to oxygen, in the process generating an electrochemical gradient across the mitochondrial inner membrane (reviewed in $\mathrm{Ha}$ tefi, 1985; Capaldi, 1988). The mammalian enzyme is composed of 13 polypeptide subunits -3 encoded in mtDNA and 10 in nuclear DNA (reviewed in Kadenbach et al., 1987; Capaldi, 1988; Chomyn and Attardi, 1987). The nuclear-coded COX subunits can be divided into two groups: those with muscle-specific isoforms (reviewed in Capaldi et al., 1988; Lomax and Grossman, 1989) and those that are identical in all tissues (Yanamura et al., 1988). The nuclear genes for these latter ubiquitous subunits are expressed consti- tutively and probably represent examples of "housekeeping" genes (Bird, 1986).

It has been possible to map human COX genes by means of Southern blot analysis of DNA from panels of somatic cell hybrids. For example, the single-copy gene for COX subunit VIII (COX8) was mapped to chromosome 11, region q12-q13 (Rizzuto et al., 1989), and the gene for COX subunit IV (COX4) to chromosome 16 region q22-qter (Darras et al., 1987; Lomax et $a l ., 1990)$. The isolation of a human COX Vb cDNA (Zeviani et al., 1988) provided a probe for cloning and mapping the $C O X 5 B$ gene, whose chromosomal location was obscured by the presence of several $C O X 5 B$ related genes or pseudogenes. We report here the isolation and DNA sequence of the expressed gene for human $\mathrm{COX}$ subunit $\mathrm{Vb}(C O X 5 B)$ and the chromosomal location of the expressed gene and seven pseudogenes, as determined by analysis of panels of somatic cell hybrids with cDNA, genomic, and intron probes.

\section{MATERIALS AND METHODS}

\section{Materials}

Restriction enzymes were from BRL, New England Biolabs, or Boehringer-Mannheim. The DNA labeling system for "random-primer" labeling and $[\alpha-$ ${ }^{35}$ S] thiodATP for DNA sequencing were from Amersham. $\left[\alpha^{32} \mathrm{P}\right] \mathrm{dCTP}$ for random primer labeling was from NEN. The Sequenase DNA sequencing kit was from USB.

Subcloning and Restriction Mapping of the COX5B Gene

Plasmid pCOX5bR3.4 containing the human $C O X 5 B$ gene was constructed by cloning a $3.4-\mathrm{kb}$ $E c o$ RI fragment from the 5 ' end of $\lambda$ COX5B- 1 into the 


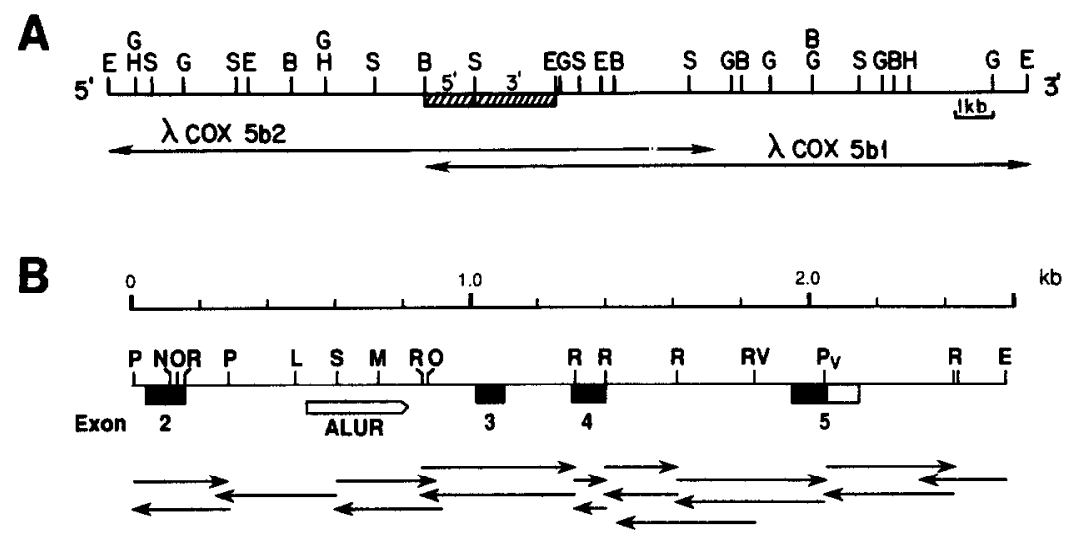

FIG. 1. Restriction maps of the COX5B gene. (A) Restriction map of the human COX5B locus, based on two overlapping genomic clones: $\lambda C O X 5 B-1$ and $\lambda$ COX5B-2. The hatched areas indicate the location and orientation of the COX5B gene, as defined by hybridization. Arrows define the genomic regions contained within each genomic clone. Restriction enzymes: B, BamHI; E, EcoRI; G, BglII; H, HindIII; S, SstI. (B) Restriction map of a 2.6-kb PSTI-EcoRI-fragment of a 3.4-kb EcoRI subclone of $\lambda$ COX5B-1 (pCOX5bR3.4) encompassing the coding regions and $3^{\prime}$-untranslated region of the COX5B gene. Filled boxes represent coding (translated) exons, open boxes the $3^{\prime}$-untranslated region, and straight lines the introns. The open arrow (designated ALUR) denotes the position and orientation of the AluI repeat in intron 2. Restriction enzymes: E, EcoRI; P, PstI; L, SalI; M, SmaI; N, NotI: O, NcoI: R, RsaI; RV, EcoRV; S, SstI; V, PvuII. Arrows below the restriction map denote the sequencing strategy for the human $C O X 5 B$ gene.

EcoRI site of the plasmid vector BlueScriptKS ${ }^{-}$ (Stratagene, La Jolla, CA). Sites for restriction enzymes that cleaved uniquely within the polylinker sequence were mapped within the genomic clone. Deletion subclones were generated by digesting the plasmid with enzymes that cleaved within both the genomic region and the polylinker, diluting the plasmid DNA to a concentration of $0.1-0.5 \mu \mathrm{g} / \mathrm{ml}$, and religating the fragments. Deletions from internal $P s t \mathrm{I}, S a l \mathrm{I}, S s t \mathrm{I}$, and $E c o \mathrm{RV}$ sites were generated in this manner and sequenced. Additional subclones of the $1.2-\mathrm{kb} S s t \mathrm{I}-E c o \mathrm{RV}$ region were generated by cloning $R s a I$ fragments into the SmaI site of pUC13.

\section{DNA Sequencing}

Dideoxy DNA sequencing (Sanger et al., 1977) was performed with Sequenase (USB) on duplex plasmid DNA (Chen and Seeberg, 1985) isolated by the alkaline lysis method (Birnboim and Doly, 1979) from mini-preps or from 250-ml cultures. Primers complementary to the T3 and T7 promoter sequences in BlueScriptKS ${ }^{-}$were used to sequence pCOX5bR3.4 and its deletion subclones. RsaI subclones in pUC13 were sequenced using the M13 universal and reverse sequencing primers. Synthetic oligonucleotide primers (20-mers) were used to obtain the sequence of complementary strands in certain regions; they were synthesized in the University of Michigan DNA Synthesis Facility on an Applied Biosystems DNA synthesizer. DNA sequences were stored and analyzed using the ASSEMGEL program of PC/GENE (Intelligenetics, Mountain View, CA).

\section{Somatic Cell Hybrids}

A panel of 16 hybrid clones derived from seven independent fusion experiments between Chinese hamster and human cell lines (for summary see YangFeng et al., 1986) was used for primary chromosomal assignment in human. Four rodent $\times$ human hybrids from series X, XVIII, and XIX containing different regions of human chromosome 2 were used for regional mapping (Alonso et al., 1988; Barton et al., 1989).

\section{Probes}

Two probes were used for primary mapping: Probe 1-a human pCOX5b.222 cDNA clone of $480 \mathrm{bp}$ (Zeviani et al., 1988); and Probe 2-a 1.2-kb SstI-EcoRV fragment from genomic clone pCOX5bRS2.0 (the SstI deletion clone of pCOX5bR3.4, which retained the $2.0-\mathrm{kb}$ region from $S s t$ t to EcoRI). Probe 2 contains exons 3 and 4, portions of introns 2 and 4 , and all of intron 3 of human $C O X 5 B$. For chromosomal assignment of the COX5B coding sequence, a 210-bp RsaI fragment (1402-1612, Fig. 2) containing a portion of intron 4 of the $C O X 5 B$ gene (Probe 3 ) was used. The probes were isolated in $0.8 \%$ low-meltingpoint agarose and labeled with $\left[\alpha-{ }^{32} \mathrm{P}\right] \mathrm{dCTP}$ by the random priming labeling method (Feinberg and Vogelstein, 1983).

\section{Genomic Southern Blot Analysis}

Human genomic DNA isolated from blood leukocytes was digested with the indicated restriction enzymes. DNA fragments $(10 \mu \mathrm{g})$ from each digest were 


\author{
EXON 2-->

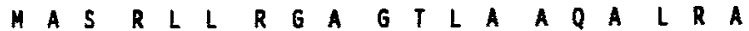 \\ 1 CTGCAGCTTG ITCCCGGĀ̄G IITTGCTGCT ÄGTCGCGGAC GCAATGGCTT CAAGGTTACT TCGCGGAGCT GGACGCTGG CCGCGCAGGC CCTGAGGGCT
}

R H P S G A A A M R S M A A S G INTRON 2-D

101 CGCGGCCCCCA GTGGCGCGGC CGCGATGCGC TCCATGGCAT CTGGAGGTAC TCGGGTCTCC GGGCGTGCCA GGGACCAGAG TGTTGCCCTC CCAGGGTGGT 201 CCCAGGGCGG CAAAGCGGCG CGGCTCGTGC AGCTTCTCGA GGTCCCAGTG GCCGCTTTAC GGTCCCCAGT GCCTCAGGCT CTGCAGGCAT CTCCCTGTAA 301 TTCTGGACCG CTGCTCCTGC CGCTCCCCGA ACTCACTCCG CTGCGAAAGT ATCCTAAACG GAGGTGCCGG GTGACCTTGG GAGGGACCGG GGCTGCCACC 401 GGGATGGGGA GGGGTCCGGC CTCCCTTCAA ACCTGCGCCC ACCTCAAGCA GAGTGGGTTC TACATGCTTT TAGACAAATG TCGACAAATT TGCCTCGGTG 501 GTTGGAGAAA GAAAGCTCA TAGGCCGGGC GCGGTGGCTC ACAACTGTAA ICCCAGCACI ITGGGAGGCC GAGGCGGACA GATCCCTGAG GICAGGAGCT 601 CAAGACCAGC CTGGCCAACA IGGTAAAACC CCGTITCTAC IAAAAATACA AAAATTAGCC GGGCGTGGTG GCGCGCGCCI GIAGTCCCAG CTACTCFGGA 701 GGCTGAGGCA GGAGAATCGC IIAAACCCGG GAGGCGGAGG IICCCGIGAG CCAACATCGC GCCAITGCAC ICCAGCCTEG GCAACAAGAG CAAAACTCCG 801 GCICAAAAAA GAAAAAAAAA GCTCCCCCGA GTGCTGCCGC ITGTGTGGAT GGGTACTTGG TGGTTCTTAG GGGACCATGG ATATGAGTAG CCTTTAGGAG 901 CTTGTGAGCC CGCTAAAACT TATACAGAAG TTTCGgGGCA CCATTTTCCT TGATCATTTC TGTTTGTAGT ITTTCTATCA GTCATTTCAG TCAGCGTCAT EXON 3-->

G G V P P T $D$ D E $E$ E O A $A$ T G L E R

1001 AATTCACGTT ATCTTCCTTT AGGTGGTGTT CCCACTGATG AAGAGCAGGC GACTGGGTTG GAGAGGGAGA TCATGCTGGC TGCAAAGAAG GGACTGG̈TA 1101 GAGAAACTCC CTTCTGTCTT CTGTGTAACT TATGGCCTTG GATGTGTTCA TAGTGGTCTC CTCTCTGGGA GTATTTGATA CAGGAAACTT GGCTTGTAGG

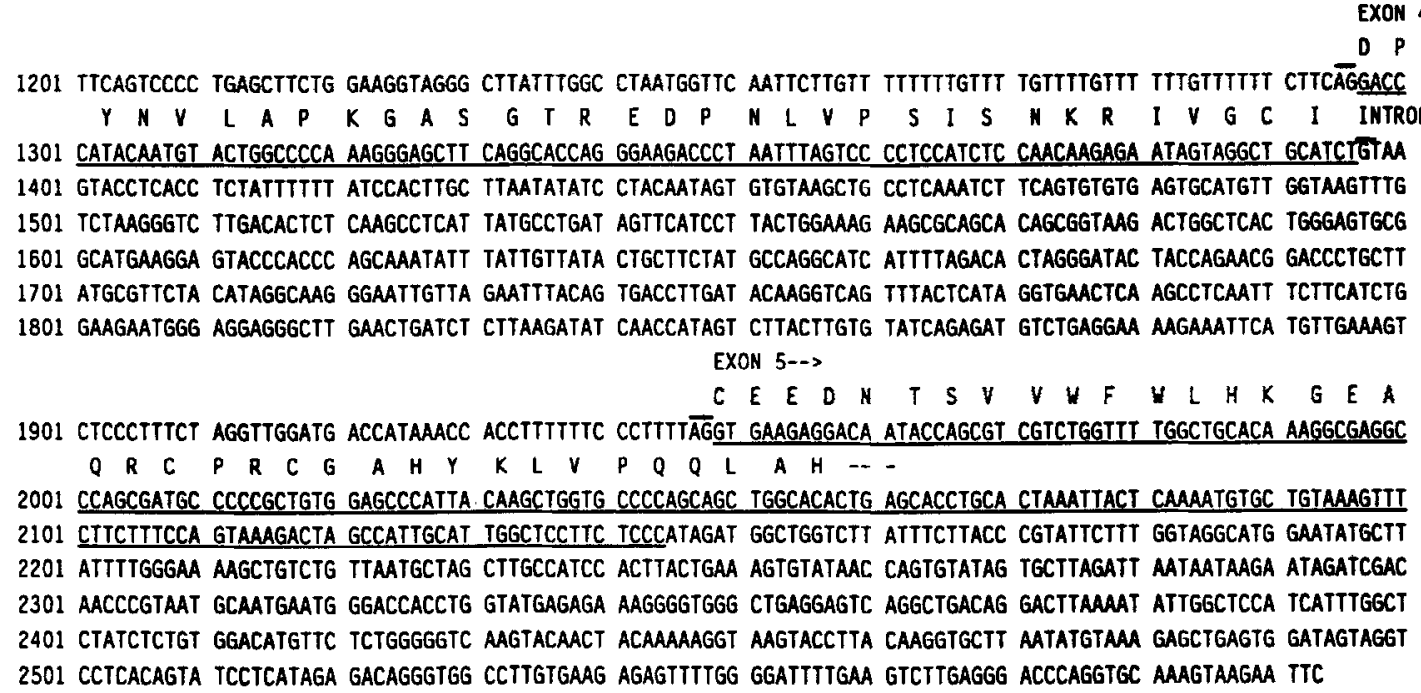

FIG. 2. DNA sequence of the human $C O X 5 B$ gene. The nucleotide sequence of 2593 bp of genomic DNA containing exons 2 through 5 and introns 2 through 4 is presented, starting in intron 1 at the $P s t I$ site, which is designated nt 1 , and continuing to the EcoRI site beyond the gene. Coding regions are underlined and the deduced amino acid sequence is presented above the DNA sequence. Consensus 5 '-donor and 3 '-acceptor splice sites, including the two potential 3 '-acceptor sequences preceding the ATG initiation codon, are overlined. The Alu repeat sequence extending from base 521 to 820 is underlined.

separated by electrophoresis on $0.8 \%$ agarose gels, denatured, and transferred to Nytran nylon membranes (Schleicher \& Schuell) by blotting. Southern blot hybridization analysis was performed at $42^{\circ} \mathrm{C}$ for $18-24$ $\mathrm{h}$ in $50 \%$ formamide, $5 \times \mathrm{SSPE}, 1 \%$ SDS, $50 \mu \mathrm{g} / \mathrm{ml}$ denatured salmon testis DNA with ${ }^{32} \mathrm{P}$-labeled cDNA probe. After hybridization, membranes were washed at $60^{\circ} \mathrm{C}$ with decreasing concentrations of SSC containing $0.1 \%$ SDS. Restriction enzymes HindIII and PstI were used for primary mapping, and HindIII was used for regional mapping. DNA from each of the hyhrid and parental control cell lines was digested with enzyme, and then fragments were separated on $0.8 \%$ agarose gels and transferred to Hybond-N membranes (Amersham) by the method of Southern (1975). The conditions for prehybridization, hybridization, and washing of filters were described previously (Hsieh et al., 1990). All filters were exposed to Kodak X-Omat $\mathrm{AR}$ films at $-70^{\circ} \mathrm{C}$ for varying lengths of time.

\section{RESULTS}

\section{Isolation of Genomic Clones for Human $\mathrm{COX} \mathrm{Vb}$}

Southern blot analysis of human genomic DNA digested with $P s t$ I revealed many fragments that hybridized with the pCOX5b cDNA (Zeviani et al., 1988). We therefore anticipated that a genomic library would contain clones encompassing different genomic regions, including several pseudogenes. To isolate the human $C O X 5 B$ gene, we screened a human genomic library (Lawn et al., 1978) containing AluIHaeIII partial digest fragments of human DNA 


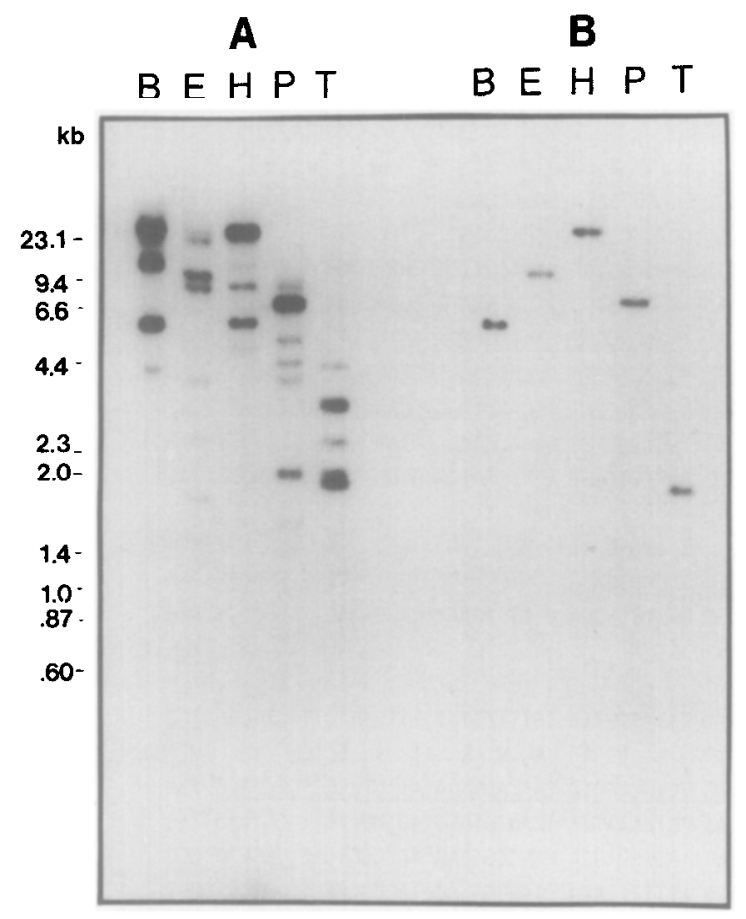

FIG. 3. COX5B-related sequences in the human genome. Genomic Southern blots of human DNA probed with (A) the pCOX5b cDNA (Probe 1) and (B) a 210-bp $R s a I$ fragment (Probe 3) from intron 4 of the $C O X 5 B$ gene. Restriction enzymes used are $\mathrm{B}$, BamHI; E, EcoRI; H, HindIII; P, PstI; T, TaqI.

cloned into the $E$ coRI site of bacteriophage $\lambda$ Charon4A (obtained from A. S. Lee with permission of Dr. T. Maniatis, Harvard University). Approximately $10^{6}$ plaques were plated and screened by plaque hybridization techniques according to standard procedures (Benton and Davis, 1977) with Probe 1 , the full-length human $\mathrm{COX} \mathrm{Vb}$ cDNA insert from pCOX5b (Zeviani et al., 1988), as hybridization probe. Phage DNA was isolated from small-scale lysates (Maniatis et al., 1982) of the six plaques that gave duplicate hybridization signals and characterized by restriction mapping and Southern blot analysis with the pCOX5b cDNA (Probe 1). EcoRI digestion revealed only two types of clones, designated $\lambda$ COX $5 B$ 1 and $\lambda$ COX5B-2 (Fig. 1A). Southern blot analysis of phage DNA revealed that each clone contained an approximately $6-\mathrm{kb}$ Pst I fragment that hybridized with the cDNA; therefore every clone isolated in this screen contained only one genomic region. Southern blot analysis with hybridization probes encoding either the $5^{\prime}$ end (a 115-bp EcoRI-NcoI fragment) or the $3^{\prime}$ end (a 100-bp PvuII-EcoRI fragment) of the cDNA indicated that both $\lambda$ COX5B-1 and $\lambda$ COX5B-2 contained the entire $C O X 5 B$ coding region. Further restriction mapping confirmed that the two clones represented overlapping clones of the same genomic region (Fig. 1A). We therefore subcloned a 3.4-kb EcoRI fragment from the $5^{\prime}$ end of $\lambda$ COX5B- 1 for more detailed analysis.

The exon-intron structure of the COX5B gene and the sequencing strategy used are presented in Fig. 1B. This 3.4-kb EcoRI fragment contained the four coding exons, designated exons $2,3,4$, and 5 . The sequence of these four exons and that of the three introns are presented in Fig. 2. Exon 2 encodes the 31 amino acids of the presequence (amino acids -31 to -1 ) plus amino acids 1 to 3 of mature $\mathrm{COX} \mathrm{Vb}$; exon 3 encodes amino acids 3 to 28 ; exon 4 encodes amino acids 29 to 62 ; and exon 5 encodes amino acids 62 to 97 plus the 83 -bp 3 -untranslated region. The DNA sequence of the coding exons and the 3 '-untranslated region in this genomic region is essentially identical to the sequence of the cDNA, confirming that this gene encodes the pCOX5b cDNA. The only discrepancy between the genomic and the cDNA sequences occurred in exon 5 . The sequence we determined for codons $77-78$ of the human $C O X 5 B$ gene is GGC$\mathrm{GAC}$, which predicts the sequence Gly-Glu, whereas the published cDNA sequence is GGG-CAG or GlyGln. Since the bovine (Zeviani et al., 1988), rat (Goto et al., 1989), and mouse (Basu and Avadhani, 1990) cDNAs have GAC (Glu) at position 78, we assume that our genomic sequence (GGC-GAC) is correct and that the sequence (GGG-CAG) in the cDNA probably represents a sequencing error.

All intron-exon junctions of the COX $5 B$ gene (Fig. 2) conformed to the consensus splice junction sequences (Sharp, 1981; Padgett et al., 1986), except for the 3 '-splice junction preceding exon 2 . The sequence preceding the ATG initiator Met codon in the pCOX5b cDNA is (T) ${ }_{13} \mathrm{CCA}-\mathrm{ATG}$; only the CA (nucleotides 42-43, Fig. 2) preceding the ATG initiator Met codon is present in the genomic sequence at the end of intron 1 . There is no consensus $3^{\prime}$-splice sequence preceding the $\mathrm{CA}$, although there are at least two potential 3 '-acceptor splice sequences just upstream at nucleotides 19-20 and 31-32. This observation and the poly $(\mathrm{dT})$ tract in the 5 '-untranslated region of this cDNA and other cDNAs isolated from this human endothelial cell library (e.g., see Fabrizi et $a l ., 1989$ ) suggested that the cDNA contained a cloning artifact at the $5^{\prime}$ end. Additional support for this hypothesis is that the genomic sequence preceding the ATG initiation Met codon agrees well with the consensus sequence proposed by Kozak (1987) for initiation of translation of eukaryotic genes, suggesting that this sequence should be part of exon 2. This artifact in the cDNA precluded mapping exon 1 (encoding the $5^{\prime}$-untranslated region) by hybridization with the pCOX5b cDNA.

\section{Chromosomal Mapping}

Southern blots of human genomic DNA probed with the pCOX5b cDNA (Probe 1) revealed several 

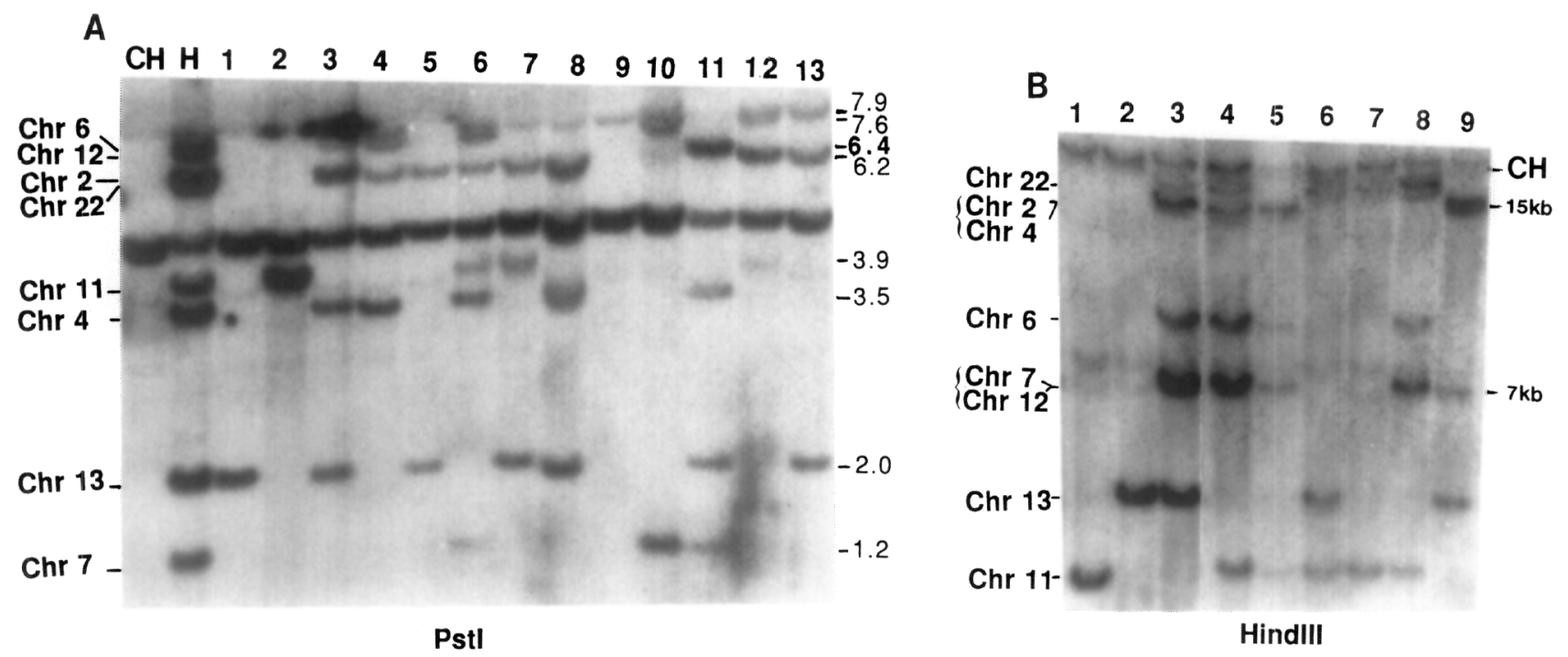

FIG. 4. Mapping of COX5B sequences. Hybridization of human COX5B cDNA (Probe 1) to PstI-digested (A) and of the genomic exon/intron Probe 2 to HindIII-digested (B) Chinese hamster $\times$ human somatic cell hybrid and control DNA revealed discordant segregation of all human fragments. The chromosomal assignments for each band are marked on the left, and sizes in kb on the right. (A) The closely migrating 7.6- and 7.9-kb human fragments are separated in the hybrids: lanes 3, 4, 6, 10, and 11 are positive for the 7.6-kb band. Similarly, the 6.4-kb human fragment containing the COX5B coding gene is separable from the 6.2-kb pseudogene fragment. Hybrids positive for the 6.4-kb fragment are in lanes 3, 8, and 11. (B) The heavy 15-kb HindIII fragment appeared to cosegregate with human chromosomes 2 and 4. After hybridization of the same filter with the intron Probe 3, the 15-kb fragment was detected in lanes 3, 4, and 9 but not in lane 5. These results led us to conclude that there are two overlapping 15.0-kb HindIII fragments that map to chromosomes 2 and 4 , with that on chromosome 2 containing the COX5B coding gene. Based on comparison with results obtained with the PstI-digested panel, two 7.0-kb HindIII fragments were postulated and assigned to chromosomes 7 and 12 .

bands in each of five different restriction digests (Fig. $3 \mathrm{~A})$; however, Southern blots probed with a unique sequence probe (Probe 3), a 210-bp RsaI fragment from intron 4, revealed a single hybridizing fragment in each digest (Fig. 3B). Initially, mapping of the human gene was attempted by hybridizing the ${ }^{32} \mathrm{P}-\mathrm{la}-$ beled cDNA probe to HindIII- and PstI-digested genomic DNA from Chinese hamster $\times$ human somatic cell hybrids and controls. Chinese hamster bands of 4.7 and $17.5 \mathrm{~kb}$ were seen in PstI- and HindIII-digested DNA, respectively (Fig. 4). The 4.7-kb PstI fragment in human was not scored because it was indistinguishable from the Chinese hamster band. We were able to assign the two $15.0-\mathrm{kb}$ HindIII fragments to different chromosomes by the intensity of hybridization and after assigning the coding gene with an intron probe. Sites on eight chromosomes were identified by the cDNA probe with both PstI and HindIII hybrid panels (Fig. 4). The same fragments hybridized with the genomic probe 2 . The presence or absence of the individual $P s t \mathrm{I}$ and HindIII fragments in the 16 hybrid cell lines is listed in Table 1 and compared with the human chromosome content of the hybrids. The PstI and HindIII fragments that represent the same genetic locus could be identified by their pattern of segregation in the hybrid cell lines. The percentage of discordant hybrids is calculated for each fragment pair and each chromosome. It is appar- ent that each fragment is concordant only with a single chromosome and that they are all present on different chromosomes.

We then used the 210-bp human intron probe (Probe 3) to determine the localization of the coding gene. A single 15.0-kb HindIII fragment (Fig. 5, lane 1) and a single 6.4-kb PstI fragment (data not shown) were detected in human control DNA, and two weakly hybridizing $H$ indIII fragments of 4.4 and $3.2 \mathrm{~kb}$ were observed in rat DNA (Fig. 5, lane 3), while no crosshybridization was detected with Chinese hamster DNA (Fig. 5, lane 2). The human 15.0-kb HindIII and 6.4-kb PstI bands were present only in hybrid clones containing human chromosome 2. No human signal was detected in hybrids not containing human chromosome 2. The presence or absence of human chromosome 2 in hybrid cell lines was in perfect concordance with that of the human COX5B signal. All other human chromosomes were excluded by at least two discordant hybrids (Table 1 ). We have assigned COX5B to region cen-q13 of chromosome 2 (Fig. 6 ) by using four hybrids containing partially overlapping regions of human chromosome 2 in the absence of an intact chromosome 2. In Table 2, the chromosomal assignments of the $C O X 5 B$ coding gene and of seven pseudogenes (COX5BP1 to COX5BP7) are summarized. Hybrid cell lines that contained defined regions of chromosomes 4 and 11 were used to localize region- 
LOMAX ET AL.

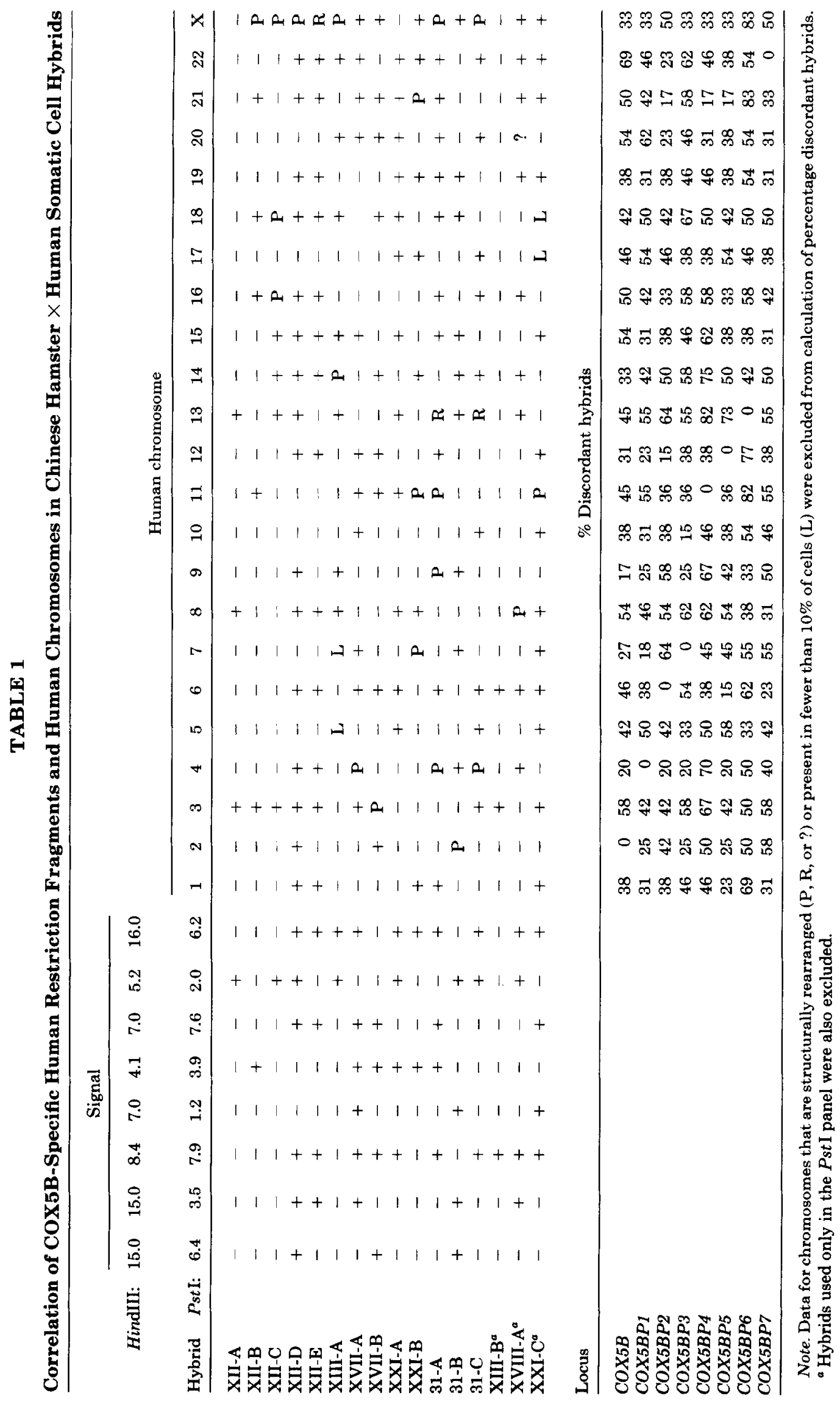




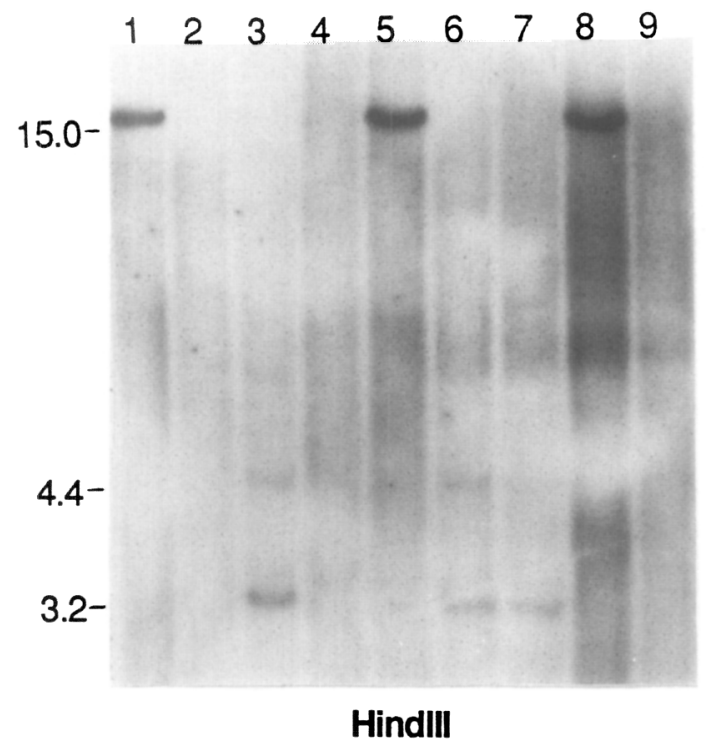

FIG. 5. Regional mapping of $C O X 5 B$ coding gene. Hybridization of ${ }^{32} \mathrm{P}$-labeled human intron probe (Probe 3 ) to a Southern blot of HindIII-digested DNA from rodent $\times$ human hybrid cell lines and controls. Lane 1, human diploid lymphoblastoid cells; lane 2, Chinese hamster cells V79/380-6; lane 3, rat hepatoma cell line; lanes 4-9, rodent $\times$ human hybrid cell lines. Lanes 5 and 8 contain the 15.0 -kb human $C O X 5 B$ fragment. Lanes 4 and 9 (Chinese hamster $X$ human hybrids) have no detectable $C O X 5 B$ signal. Lanes 6 and 7 contain only the 4.4- and 3.2-kb rat signals. DNA in lanes 4-7 was extracted from hybrids that have retained different regions of human chromosome 2 ; lane 4 , hybrid $C$; lane 5 , hybrid B; lane 6, hybrid A; lane 7, hybrid D (Fig. 6). DNA in lane 8 was from hybrid that has retained an intact human chromosome 2, and that in lane 9 had no chromosome 2.

ally COX5BP1 and COX5BP4, respectively (data not shown).

\section{DISCUSSION}

\section{Structural Features of the COX5B Gene}

The $C O X 5 B$ gene is composed of five exons and four introns. Exon 1, which has not yet been localized, encodes only the $5^{\prime}$-untranslated region; exon 2 the presequence; and exons 3,4 , and 5 the remainder of the cDNA. It has been suggested that exons encode functional domains of proteins; thus it is sometimes possible to predict the exon-intron structure of a gene on the basis of functional domains of the protein. One prominent feature of most proteins destined for mitochondria is a short (20- to 40 -amino-acid) basic $\mathrm{N}$ terminal extension (presequence) that directs precursors to the mitochondrial outer membrane. Thus far, all genes for mitochondrial proteins with presequences have separate exons encoding the presequence. In the $C O X 5 B$ gene, this functional domain also is encoded by a separate exon, exon 2 , as in the bovine $\operatorname{COX} 4$ gene, the only other characterized $\operatorname{COX}$

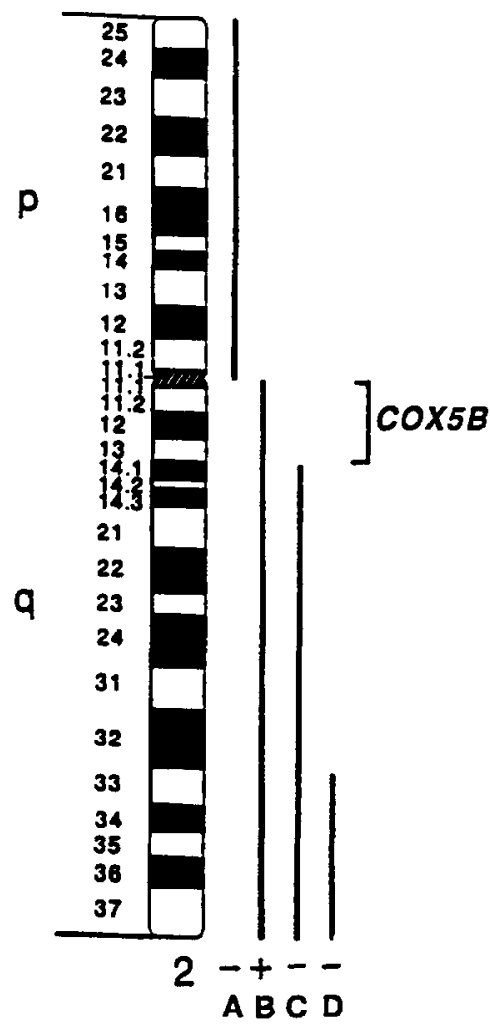

FIG. 6. Localization of $C O X 5 B$ coding gene on chromosome 2 . Vertical hars illustrate the regions of chromosome 2 present in somatic cell hybrids A-D. A + indicates hybrid positive for human $C O X 5 B$ sequence, and - indicates hybrid negative for human $C O X 5 B$ sequence.

gene encoding a subunit with a presequence (Bachman et al., 1987). Goto et al. (1989) recently reported the sequence of a rat $\mathrm{COX}$ subunit $\mathrm{Vb} \mathrm{cDNA}$, which they assumed to be synthesized without a presequence, based on the fact that the rat cDNA, like the human pCOX5b cDNA, had an ATG Met codon preceding the sequence of the mature protein. However, the 54-bp rat sequence preceding this Met is an open

TABLE 2

Chromosomal Assignment of Different Fragments That Hybridized with the COX5B Probes 1 and 2

\begin{tabular}{lllr}
\hline & & \multicolumn{2}{c}{ Fragment size (kb) } \\
\cline { 3 - 4 } Gene name & Chromosome & Pst I & HindIII \\
\hline COX5B & 2 cen-q13 & 6.4 & 15.0 \\
COX5BP1 & 4 cen-q31 & 3.5 & 15.0 \\
COX5BP2 & 6 & 7.9 & 8.4 \\
COX5BP3 & 7 & 1.2 & 7.0 \\
COX5BP4 & $11 \mathrm{q}$ & 3.9 & 4.1 \\
COX5BP5 & 12 & 7.6 & 7.0 \\
COX5BP6 & 13 & 2.0 & 5.2 \\
COX5BP7 & 22 & 6.2 & 16.0 \\
\hline
\end{tabular}


reading frame with a high degree of both nucleotide ( $82 \%)$ and amino acid sequence identity ( $84 \%)$ to the human sequence. A longer mouse $\mathrm{cDNA}$ (Basu and Avadhani, 1990) also contains an in-frame Met codon upstream, thus predicting a presequence. We conclude, therefore, that the rat clone is a partial cDNA lacking the 5 '-untranslated region and the first $12 \mathrm{co}$ dons of the presequence.

The human cytochrome $c_{1}$ gene is the only gene in which two exons encode the presequence (Suzuki et al., 1989); however, because the cytochrome $c_{1}$ precursor is processed in two separate steps, this two-exon structure still correlates with the two functional domains of the presequence. Thus, Gilbert's hypothesis for exon shuffling (Gilbert, 1985) appears to be valid in this case.

An additional feature common to most nuclearcoded COX subunits is a hydrophobic, putative membrane-spanning region flanked by hydrophilic $\mathrm{N}$-terminal and C-terminal domains. COX subunits $\mathrm{Va}$ and $\mathrm{Vb}$, however, are the two nuclear-coded COX subunits that have no such hydrophobic, membranespanning regions; it has also been determined experimentally that these two subunits do not span the mitochondrial inner membrane (Zhang and Capaldi, 1989). Thus, it was not possible a priori to predict the intron-exon structure of this gene.

None of the four introns of the COX $5 B$ gene sequenced thus far is larger than $1 \mathrm{~kb}$. The largest, intron 2, contains an Alu repeat (nts 513-820, Fig. 2) with $92 \%$ sequence identity to the consensus genomic Alu repeat sequence (Schmid and Shen, 1985). This repeat is more similar to the consensus sequence for the older Alu repeat family than to the more recently evolved repeat family (Deininger and Slagel, 1988) and also contributes to the high G-C content of the intron. Intron 3 contained several interesting repeats, a direct repeat of CTTCTG near the beginning of the intron (nts 1111-1124, Fig. 2) and several direct repeats of TTGTTTT near the $3^{\prime}$ end (nts 1256-1288, Fig. 2) which could potentially be used to develop PCR markers to detect RFLPs.

\section{The COX5B Gene May Be a Housekeeping Gene}

Proteins that are essential components of intermediary metabolism and are found in most cell types are said to be encoded by "housekeeping" genes. Bird (1986) noted that housekeeping genes have several common structural features, most notably a high frequency of the rare dinucleotide $\mathrm{CpG}$ at their $5^{\prime}$ ends, resulting in a large number of HpaII sites (CCGG). The promoter regions of housekeeping genes also lack certain consensus sequence elements such as TATA and CAAT boxes known to be associated with tissuespecific expression of genes (Maniatis et al., 1987), but have multiple binding sites ( $\mathrm{G}-\mathrm{C}$ boxes) for the transcription factor SP1 (Dynan and Tjian, 1985). The COX5B gene also contains a large number of $H p a I I$ sites near the $5^{\prime}$ end, i.e., in exon 2 and intron 1 , and at least two consensus SP1 binding sites in the limited region of the first intron sequenced thus far (data not shown). These features suggest that the $C O X 5 B$ gene is also a housekeeping gene. Whether there are additional regulatory promoter or enhancer elements for respiratory proteins, such as NRF-1 binding sites found in the promoter of the cytochrome $c$ gene (Evans and Scarpulla, 1989), awaits mapping and further analysis of the promoter region.

\section{Chromosomal Localization of the Expressed COX5B Gene}

We have identified eight different chromosomal sites of hybridization with probes containing both exon and intron sequences of $C O X 5 B$. Since only the gene on human chromosome 2 , region cen-q13, hybridized to an intron probe, we assigned the $C O X 5 B$ coding gene to this site. All the human fragments hybridized strongly under high stringency hybridization and washing conditions. This suggests that these sequences are pseudogenes of $C O X 5 B$ instead of partially related genes. Two other genes, INHBB (inhibin- $\beta_{\mathrm{B}}$ ) and $M A L$ ( $\mathrm{T}$ cell differentiation protein), have been assigned to the same region in the same set of hybrids (Barton et al., 1989; Alonso et al., 1988). Genes for other nuclear-encoded subunits of cytochrome $c$ oxidase have been mapped to different chromosomes: subunit IV (COX4) to chromosome 16, region q22-qter (Darras et al., 1987; Lomax et al., 1990) and subunit VIII (COX8) to chromosome 11, region q12-q13 (Rizzuto et al., 1989).

\section{ACKNOWLEDGMENTS}

We thank Dr. A. S. Lee, USC, for the human genomic library, Dr. E. A. Schon, Columbia University, for the pCOX5b cDNA, E. Ziaja for screening the human genomic library, and D. BeMent and E. Gamliel for excellent technical assistance. This research was supported by NIH Grants GM30866 (M.I.L.) and GM26105 (U.F.), by NSF Grant DMB-90-05580 (M.I.L.), and by the Howard Hughes Medical Institute.

\section{REFERENCES}

1. Alonso, M. S., Barton, D. E., and Francke, U. (1988). Assignment of the T-cell differentiation gene MAL to human chromosome 2, region cen-q13. Immunogenetics 27: 91-95.

2. Bachman, N. J., LomaX, M. I., AND Grossman, L. I. (1987). Two bovine genes for cytochrome $c$ oxidase subunit IV: A processed pseudogene and an expressed gene. Gene 55: 219229.

3. Barton, D. E., Yang-Feng, T. L., Mason, A. J., Seeburg, P. H., AND Francke, U. (1989). Mapping of genes for inhibin 
subunits $\alpha, \beta_{\mathrm{A}}$, and $\beta_{\mathrm{B}}$ on human and mouse chromosomes and studies of jsd mice. Genomics 5: 91-99.

4. Basu, A., AND Avadhani, N. G. (1990) Nucleotide sequence of cDNA for nuclear encoded subunit $\mathrm{Vb}$ of mouse cytochrome-c oxidase. Biochim. Biophys. Acta 1087: 98-100.

5. Benton, W. D., AND DAvis, R. W. (1977). Screening lambda gt recombinant clones by hybridization to single plaques in situ. Science 196: 180-182.

6. BIRD, A. P. (1986). CpG-rich islands and the function of DNA methylation. Nature 321: 209-213.

7. BIRNBoIM, H. C., AND DOLY, J. (1979). A rapid alkaline extraction procedure for screening recombinant plasmid DNA. Nucleic Acids Res. 7: 1513.

8. CAPALDI, R. A. (1988). Mitochondrial myopathies and respiratory chain proteins. Trends Biochem. Sci. 13: 144-148.

9. Capaldi, R. A., Halphen, D. G., Zhang, Y.-Z., and YanaMURA, W. (1988). Complexity and tissue specificity of the mitochondrial respiratory chain. J. Bioenerg. Biomemb. 20: 291-311.

10. Chen, E. Y., AND Skeberg, P. H. (1985). Supercoil sequencing: A fast and simple method for sequencing plasmid DNA. DNA 4: 165.

11. Chomyn, A., AND ATTARdi, G. (1987). Mitochondrial gene products. In "Current Topics in Bioenergetics" (C. P. Lee, Ed.), Vol. 15, pp. 295-329, Academic Press, New York.

12. Darras, B. T., Zeviani, M., Schon, E. A., AND Francke, U. (1987). Sequences homologous to cytochrome $c$ oxidase subunit IV are located on human chromosomes 14q21-qter and 16q22-q24. Cytogenet. Cell Genet. 46: 603 (abstract).

13. DeININGER, P. L., AND SLAGEL, V. K. (1988). Recently amplified Alu family members share a common parental Alu sequence. Mol. Cell. Biol. 8: 4566-4569.

14. Dynan, W. S., AND TiJan, R. (1985). Control of eukaryontic mRNA synthesis by sequence-specific DNA binding proteins. Nature 316: 774-778.

15. Evans, M. J., AND SCARPULLA, R. C. (1989). Interaction of nuclear factors with multiple sites in the somatic cytochrome c promoter. J. Biol. Chem. 264: 14361-14368.

16. Fabrizi, G. M., Rizzuto, R., Nakase, H., Mita, S., KadenBACH, B., AND SCHON, E. A. (1989). Sequence of a cDNA specifying subunit VIIa of human cytochrome $c$ oxidase. Nucleic Acids Res. 17: 6409.

17. Feinberg, A., AND Vogelstein, B. (1983). A technique for radiolabeling DNA restriction endonuclease fragments to high specific activity. Anal. Biochem. 132: 6-13.

18. GILBERT, W. (1985). Genes in pieces revisited. Science 228: 823-824.

19. Goto, Y., Amuro, N., and Okazaki, T. (1989). Nucleotide sequence of cDNA for rat liver and brain cytochrome c oxidase subunit VIa (Vb). Nucleic Acids Res. 17: 6388.

20. HateFI, Y. (1985). The mitochondrial electron transport and oxidative phosphorylation system. Annu. Rev. Biochem. 54: 1015-1069.

21. Hsieh, C.-L., Sturm, R., Herr, W., and Francke, U. (1990). The gene for the ubiquitous octamer-binding protein Oct- 1 is on human chromosome 1 , region cen-q12, and near Ly-22 and Ltw-4 on mouse chromosome 1. Genomics 6: 666672.

22. KaDENBach, B., KuHN-NeNTwig, L., AND Buge, U. (1987). In "Current 'Topics in Bioenergetics" (C. P. Lee, Ed.), Vol. 15, pp. 114-162, Academic Press, New York.
23. KozAK, M. (1987). An analysis of 5 -noncoding sequences from 699 vertebrate messenger RNAs. Nucleic Acids Res. 15: 8125-8148.

24. Lawn, R. M., Fritsch, E. F., Parker, R. C., Blake, G., AND MANIATIS, T. (1978). The isolation and characterization of a linked $\delta$ - and $\beta$-globin gene from a cloned library of human DNA. Cell 15: 1157-1174.

25. Lomax, M. I., AND Grossman, L. I. (1989). Tissue-specific genes for respiratory proteins. Trends Biochem. Sci. 14: 501503.

26. LomaX, M. I., Welch, M. D., Darras, B. T., Francke, U., AND GrossmaN, L. I. (1990). Novel use of a chimpanzee pseudogene from chromosomal mapping of human COX IV. Gene 86.

27. Maniatis, T., Fritsch, E. F., AND SambrooK, J. (1982) "Molecular Cloning, A Laboratory Manual," Cold Spring Harbor Laboratory, Cold Spring Harbor, NY.

28. Maniatis, T., Goodbourn, S., ANi Fischer, J. A. (1987). Regulation of inducible and tissue-specific gene expression. Science 236: 1237-1245.

29. Padgett, R. A., Grabowski, P. J., Konarska, M. M. SEILER, S., AND ShARP, P. A. (1986). Splicing of messenger RNA precursors. Annu. Rev. Biochem. 55: 1119-1150.

30. Rizzuto, R., Nakase, H., Darras, B., Francke, U., Fabrizi, G. M., Mengel, T., Walsh, F., KadenBach, B., AND SchoN, E. A. (1989). Gene specifying subunit VIII of human cytochrome $c$ oxidase is localized to chromosome 11 and is expressed in both muscle and non-muscle tissues. J. Biol. Chem. 264: 10595-10600.

31. SANGer, F., Nicklen, S., AND Coulson, A. R. (1977). DNA sequencing with chain-terminating inhibitors. Proc. Natl. Acad. Sci. USA 74: 5463-5467.

32. SCHMID, C. W., AND SHEN, C.-K. J. (1985). In "Molecular Evolutionary Genetics" (R. J. McIntyre, Ed.), pp. 323-356, Plenum, New York.

33. SharP, P. A. (1981). Speculations on RNA splicing. Cell 23: 643-646.

34. Southern, E. (1975). Detection of specific sequences among DNA fragments separated by gel electrophoresis. . Mol. Biol. 98: 503-517.

35. Suzuki, H., Hosokawa, Y., Nishikimi, M., aNd Ozawa, T. (1989). Structural organization of the human mitochondrial cytochrome $c_{1}$ gene. J. Biol. Chem. 264: 1368-1374.

36. Weiner, A. M., Deininger, P. L., and Efstratiadis, A. (1986). Annu. Rev. Biochem. 55: 631-661.

37. Yamada, M., Amuro, N., Goto, Y., AND OKaZaKI, T. (1990). Structure of the rat gene for cytochrome $c$ oxidase subunit IV. J. Biol. Chem. 265: 7687-7692.

38. Yanamura, W., Zhang, Y.-Z., TakimiYa, S., AND CaPaldi, R. A. (1988). Tissue specific differences between heart and liver cytochrome $c$ oxidase. Biochemistry 27: 4909-4914.

39. Yang-Feng, T. L., DeGennaro, L. J., and Francke, U. (1986). Proc. Natl. Acad. Sci. USA 83: 8679-8683.

40. Zeviani, M., Sakoda, S., Sherbany, A. A., Nakase, H., RizzUTo, R., SamitT, C. E., DiMauro, S., AND Schon, E. A. (1988). Sequence of cDNAs encoding subunit $\mathrm{Vb}$ of human and bovine cytochrome c oxidase. Gene 65: 1-11.

41. Zhang, Y.-Z., AND Capald, R. A. (1989). Subunit composition of the transmembrane parts of beef heart cytochrome $c$ oxidase. Ann. N.Y. Acad. Sci. 555: 3-7. 